\title{
Microscopy at the Frontiers of Science
}

\section{2nd Joint Congress of the Portuguese and Spanish Microscopy Societies}

\author{
18-21 October 2011 \\ University of Aveiro, Portugal
}

\author{
António José Calado \\ Department of Biology and GeoBioTec Research Unit \\ University of Aveiro, 3810-193 Aveiro, Portugal
}

Ana Maria R. Senos

Department of Materials and Ceramic Engineering, CICECO

University of Aveiro, 3810-193 Aveiro, Portugal 
The 2nd Joint Congress of the Portuguese and Spanish Microscopy Societies: Microscopy at the Frontiers of Science assembled over 220 researchers who, for four exciting days, shared their knowledge and experience on a very wide scope of Microscopy and Microanalysis applications and developments. The present Proceedings volume gathers 62 peer-reviewed extended abstracts covering a vast range of research areas, both in Life and in Materials Sciences. Many upto-date topics are covered giving truly an overview of the use of microscopy techniques at the frontiers of science.

We gratefully acknowledge the following sponsors: FEI; Leica Microsystems; Oxford Instruments; CICECO research Unit, University of Aveiro; Serviços de Acção Social, University of Aveiro; Sociedade Portuguesa de Microscopia; Sociedad de Microscopía de España; IZASA; ScienTec Ibérica; Aname, Instrumentación Cientifica; paralab; MonoComp, Instrumentación s.a.; ZEISS; LASER 2000; Decimal; LABOR; FEDELCO; Auto Viação da Murtosa; Caixa Geral de Depósitos; Museu de Aveiro; Aliança, Vinhos de Portugal; Turismo Centro de Portugal; Pizzarte; APOMA, Associação de Produtores de Ovos Moles de Aveiro; Centenário, Restaurante. We further thank Sofia Senos for secretarial assistance. 